\title{
Whole-body Insulin Resistance is Associated with Elevated Serum $\alpha$-fetoprotein Levels in Patients with Chronic Hepatitis $\mathrm{C}$
}

\author{
Yasunori Kawaguchi ${ }^{1}$, Toshihiko Mizuta ${ }^{1}$, Yuichiro Eguchi ${ }^{1}$, Eiichi Sakurai ${ }^{2}$, \\ Yoichi Motomura ${ }^{2}$, Hiroshi Isoda ${ }^{1}$, Takuya Kuwashiro ${ }^{1}$, Satoshi Oeda ${ }^{1}$, Shinji Iwane ${ }^{1}$, \\ Hirokazu Takahashi ${ }^{1}$, Keizo Anzai ${ }^{1}$ and Iwata Ozaki ${ }^{1}$
}

\begin{abstract}
Objective Little is known about the relationship between elevated serum $\alpha$-fetoprotein (AFP) levels and insulin resistance, which adversely influence the clinical course of chronic hepatitis $\mathrm{C}$ (CHC). Therefore, we investigated the association between serum AFP and insulin resistance in patients with CHC.

Methods We retrospectively investigated 300 patients with $\mathrm{CHC}$ without hepatoma who underwent liver biopsies and oral glucose tolerance tests. Patients taking antidiabetic drugs were excluded. We analyzed factors associated with elevated AFP levels $(\geq 10.0 \mathrm{ng} / \mathrm{mL})$ in 265 eligible patients. Twenty patients with a homeostasis model assessment for insulin resistance value of $\geq 2.0$ and a whole-body insulin sensitivity index of $<5.0$ received prospective lifestyle intervention.

Results A univariate analysis showed that the body mass index, platelet count, levels of albumin, aspartate aminotransferase, alanine aminotransferase and $\gamma$-glutamyl transpeptidase, glucose metabolism, hepatic inflammation, fibrosis and steatosis were associated with elevated AFP levels. In a multivariate analysis, a platelet count of $<15 \times 10^{4} / \mu \mathrm{L}$, aspartate aminotransferase level of $\geq 50 \mathrm{IU} / \mathrm{L}, \gamma$-glutamyl transpeptidase level of $\geq 35$ IU/L, whole-body insulin sensitivity index of $<5.0$ and stage 3-4 fibrosis were independently associated with an elevated AFP level. A Bayesian Network analysis showed that the aspartate aminotransferase level, whole-body insulin sensitivity index and hepatic fibrosis were directly associated with an elevated AFP level. The lifestyle intervention significantly improved the serum AFP level, homeostasis model assessment for insulin resistance and whole-body insulin sensitivity index.

Conclusion Whole-body insulin resistance is associated with an elevated serum AFP level in patients with CHC. Lifestyle interventions targeting insulin resistance can reduce the serum AFP level and may ameliorate the clinical course of CHC.
\end{abstract}

Key words: $\alpha$-fetoprotein, hepatitis $\mathrm{C}$, whole-body insulin resistance, Bayesian Network analysis, lifestyle intervention

(Intern Med 52: 2393-2400, 2013)

(DOI: 10.2169/internalmedicine.52.0992)

\section{Introduction}

Approximately 170 million people worldwide have persistent hepatitis $\mathrm{C}$ virus (HCV) infection (1), the leading cause of liver cirrhosis and hepatocellular carcinoma $[\operatorname{HCC}(2,3)]$.
The serum $\alpha$-fetoprotein (AFP) level is an important predictor of the clinical course in patients with chronic hepatitis $\mathrm{C}$ (CHC), as elevated serum AFP levels are associated with a low viral response rate to interferon [IFN (4)], advanced fibrosis (5-7) and a high frequency of $\operatorname{HCC}(6,8-10)$. Although IFN can lead to biochemical improvement and eradi-

${ }^{1}$ Department of Internal Medicine, Saga Medical School, Japan and ${ }^{2}$ National Institute of Advanced Industrial Science and Technology, Japan Received for publication May 14, 2013; Accepted for publication June 18, 2013

Correspondence to Dr. Toshihiko Mizuta, mizutat@cc.saga-u.ac.jp 
cation of $\mathrm{HCV}$, which reduces the risk of $\mathrm{HCC}(11)$, the clinical impact of $\mathrm{HCV}$ eradication on $\mathrm{HCC}$ prevention is less significant in older patients than in younger patients (8). Nevertheless, prolonged IFN therapy can decrease the serum AFP levels and thus prevent hepatocarcinogenesis, even in elderly patients (10).

Recent studies have shown that insulin resistance (IR) in $\mathrm{HCV}$-infected patients is associated with the response to antiviral therapy (12-15), progression of fibrosis (12, 16-18) and development of HCC (19). Although HCV itself can evoke hepatic IR (16) and systemic IR (20), we previously reported that visceral fat accumulation is more strongly associated with IR in patients with $\mathrm{CHC}$ than in patients with non-alcoholic fatty liver disease (21). Therefore, it is likely that reducing visceral fat via lifestyle modification can improve IR in $\mathrm{HCV}$-infected patients.

These findings indicate that the serum AFP levels and IR indices, both of which are noninvasively assessed, are significantly associated with the clinical course in HCVinfected patients. However, little is known about the relationship between the serum AFP levels and IR in patients with CHC. Therefore, we conducted a retrospective study to identify clinical factors, including glucose metabolism and histologic findings, associated with high elevated serum AFP levels in $\mathrm{HCV}$-infected patients with no evidence of HCC. We also conducted a pilot study to determine whether lifestyle modification can improve IR or other clinical factors, including the serum AFP levels, in patients with CHC.

\section{Materials and Methods}

\section{Patients}

We conducted a retrospective study of $300 \mathrm{HCV}$-infected patients with no evidence of HCC who visited Saga Medical School Hospital between January 2004 and March 2010. Patients who underwent a liver biopsy and a 75-g oral glucose tolerance test (OGTT) were included in the analysis, while patients taking antidiabetic drugs were excluded. We set the cutoff value for AFP as $10.0 \mathrm{ng} / \mathrm{mL}$ because an even slightly elevated AFP level is a risk factor for $\operatorname{HCC}(6,9)$. We analyzed factors associated with elevated AFP levels ( $\geq 10.0 \mathrm{ng} /$ $\mathrm{mL}$ ) in 265 patients who met these criteria, including 137 men and 128 women, with a median age of 58 years (range: 24-75 years).

Between June 2007 and March 2009, we conducted a pilot study to investigate whether lifestyle intervention can improve IR or other clinical factors, including the serum AFP levels, in patients with CHC. Only patients with no evidence of HCC whose homeostasis model assessment for insulin resistance (HOMA-IR) value was $\geq 2.0$ (15) were enrolled. There were 11 men and nine women, with a median age of 60 years (range: $37-71$ years). The whole-body insulin sensitivity index (WBISI) was $<5.0$ in all 20 patients. The study protocol was approved by the Institutional Review Board of Saga Medical School Hospital in accordance with the ethical guidelines of the Declaration of Helsinki (1975, as revised in 1983), and written informed consent was obtained from all patients.

\section{Clinical and laboratory assessments}

All demographic and laboratory data were collected at the time of the liver biopsy. In the pilot study, some data were also collected after the intervention. The demographic data included sex, age, body mass index (BMI; $\mathrm{kg} / \mathrm{m}^{2}$ ), alcohol consumption and history of IFN therapy. Alcohol consumption was classified into three groups: none, occasionally $(<140 \mathrm{~g} /$ week) or regularly $(\geq 140 \mathrm{~g} /$ week). Venous blood samples were obtained after a 12-hour overnight fast for hematology and blood chemistry examinations. The serum AFP level (ng/mL) was measured using a chemiluminescent immunoassay kit (Abbott Japan, Tokyo, Japan). For the OGTT, the patients ingested a solution containing $75 \mathrm{~g}$ of glucose, and venous blood samples were collected at 0,30 , 60, 90 and 120 minutes to measure the plasma glucose (PG; $\mathrm{mg} / \mathrm{dL}$ ) and serum insulin (SI; $\mu \mathrm{U} / \mathrm{mL}$ ) levels. The PG levels were determined using the glucokinase method and the SI levels were measured using a chemiluminescent immunoassay kit (Abbott Japan). Glucose tolerance was evaluated according to the World Health Organization criteria (22). Briefly, normal glucose tolerance (NGT) was defined as a fasting PG (FPG) level of $<110 \mathrm{mg} / \mathrm{dL}$ and a 2-hour PG level of $<140 \mathrm{mg} / \mathrm{dL}$. Impaired fasting glycemia (IFG) was defined as an FPG level of 110-126 mg/dL and a 2-hour PG level of $<140 \mathrm{mg} / \mathrm{dL}$. Impaired glucose tolerance (IGT) was defined as an FPG level of $<126 \mathrm{mg} / \mathrm{dL}$ and a 2-hour PG level of 140-200 mg/dL. Diabetes mellitus (DM) was defined as an FPG level of $\geq 126 \mathrm{mg} / \mathrm{dL}$ or a 2-hour PG level of $\geq 200 \mathrm{mg} / \mathrm{dL}$. The indices of basal insulin secretion and insulin sensitivity were evaluated using the homeostasis model assessment (HOMA) method (23), as follows:

$\beta$ cell function $($ HOMA- $\beta$ ) $=$ fasting SI (FSI)

$$
\times 360 /[\text { FPG-63] }
$$

Insulin resistance $(\mathrm{HOMA}-\mathrm{IR})=\mathrm{FPG} \times \mathrm{FSI} / 405$

The WBISI (24) was calculated as $10,000 /(\mathrm{FPG} \times \mathrm{FSI} \times$ mean PG 0-120x mean SI 0-120) $)^{0.5}$.

In the pilot study, we also measured the serum adiponectin $(\mu \mathrm{g} / \mathrm{mL})$, leptin $(\mathrm{ng} / \mathrm{mL})$ and soluble tumor necrosis factor receptor 2 (sTNFR2; pg/mL) levels before and after the lifestyle intervention using a Human Adiponectin ELISA Kit (Otsuka Pharmaceutical Co., Ltd., Tokyo, Japan), a Human Leptin RIA Kit (Millipore Corporation, Billerica, MA, USA) and a Quantikine Human sTNFRII/TNFRSF1B Immunoassay (R\&D SYSTEMS Inc., Minneapolis, MN, USA).

Among the patients who underwent abdominal computed tomography, the visceral fat area (VFA; $\mathrm{cm}^{2}$ ) was measured at the umbilical level and calculated using the Fat Scan software program [N2 Systems, Osaka, Japan (25)].

\section{Liver histology}

A percutaneous liver biopsy was performed using a Super-Core ${ }^{\mathrm{TM}}$ Biopsy Instrument (Medical Device Technolo- 
gies, Inc., Gainesville, FL, USA) under ultrasound guidance. In each patient, a 15-mm-long liver biopsy specimen was fixed in $10 \%$ formalin, embedded in paraffin, sectioned and stained with Hematoxylin and Eosin staining and Azan for a histologic evaluation. The degree of histologic hepatic fibrosis and inflammation was scored using the METAVIR scoring system (26). Based on the degree of lymphocyte infiltration and hepatocyte necrosis, the level of inflammation was classified from A0 to A3, with a higher score indicating more severe inflammation. Fibrosis was graded from F0 to F4 as follows: F0, no fibrosis; F1, portal fibrosis without septa; F2, portal fibrosis with rare septa; F3, numerous septa without cirrhosis; and F4, cirrhosis. Steatosis was quantified as the percentage of hepatocytes that contained fat droplets classified into three groups: $<5 \%, 5-30 \%$ and $\geq 30 \%$.

\section{Lifestyle intervention}

The ideal body weight $(\mathrm{kg})$ was calculated as $22 \times$ [height $(\mathrm{m})]^{2}$. A dietitian instructed each patient to maintain a total calorie intake of 25-35 kcal/ideal body weight/day according to the level of daily activity. The exercise intervention was based on the 'Exercise and Physical Activity Guide for Health Promotion 2006' published by the Ministry of Health, Labour and Welfare of Japan (27). Briefly, the patients were recommended to walk a minimum of 8,000 steps every day on flat terrain while wearing a pedometer. The patients were also instructed to record their diet and exercise activities in a diary. The lifestyle intervention was continued for $>3$ months with the goal of reducing the HOMA-IR to $<2$.0. In patients with limited improvements in IR, the intervention was discontinued at the discretion of the attending physician.

\section{Statistical analysis}

Continuous variables are presented as the median (range). Comparisons between groups were made using the MannWhitney $U$ test for continuous variables and the $\chi^{2}$ test or Fisher's exact probability test for categorical data. A multiple logistic regression analysis was used to identify factors independently associated with an elevated serum AFP level. Wilcoxon's signed-rank test was performed to analyze the paired samples. Values of $\mathrm{p}<0.05$ were considered to be statistically significant.

A Bayesian Network $(28,29)$ is a directed acyclic graph that represents a joint probability distribution for a set of variables. Each node on the graph represents a variable, and a link between two nodes indicates a direct dependency between the variables. In the retrospective study, we used a Bayesian Network analysis to identify factors directly associated with an elevated serum AFP level.

\section{Results}

\section{Retrospective study}

The prevalence of an elevated AFP level ( $\geq 10 \mathrm{ng} / \mathrm{mL})$ was
$22.3 \%(59 / 265)$. Table 1 shows the characteristics of the patients stratified according to the serum AFP level $(<10$ vs. $\geq 10 \mathrm{ng} / \mathrm{mL}$ ). A univariate analysis showed that BMI, the platelet count, the aspartate aminotransferase (AST), alanine aminotransferase (ALT), $\gamma$-glutamyl transpeptidase $(\gamma$-GTP), triglyceride, high-density lipoprotein cholesterol (HDL-C) and albumin levels, HOMA-IR, WBISI, visceral obesity, hepatic inflammation, fibrosis and steatosis were associated with an elevated AFP level (Table 1). Variables with $\mathrm{p}<0.01$ were used in the multiple logistic regression analysis. In terms of glucose metabolic factors, we included WBISI, as this factor was more strongly associated with the serum AFP level than the other indices. The VFA was excluded from this analysis because data were missing for a number of patients. The multiple logistic regression analysis showed that a platelet count of $<15 \times 10^{4} / \mu \mathrm{L}$ (odds ratio [OR]: $2.74,95 \%$ confidence interval [CI]: 1.27-5.91, $\mathrm{p}=0.01$ ), an AST level of $\geq 50 \mathrm{IU} / \mathrm{L}$ (OR: 3.46, 95\% CI: 1.24-9.65, $\mathrm{p}=0.018$ ), a $\gamma-$ GTP level of $\geq 35$ IU/L (OR: 2.43, 95\% CI: 1.03-5.71, $\mathrm{p}=$ 0.042 ), a WBISI of $<5.0$ (OR: $3.55,95 \%$ CI: $1.56-8.09, \mathrm{p}=$ 0.003 ) and stage $3-4$ fibrosis (OR: $3.71,95 \%$ CI: 1.43-9.58, $\mathrm{p}=0.007)$ were independently associated with an elevated AFP level (Table 2). The prevalence of an elevated AFP level according to the WBISI and fibrosis was $8.3 \%$ (11/ $133)$ and $36.4 \%(48 / 132)$ for a WBISI of $\geq 5.0$ and $<5.0$, respectively, and $14.7 \%(33 / 224)$ and $63.4 \%$ (26/41) for fibrosis stage 0-2 and 3-4, respectively (Fig. 1). For the Bayesian Network analysis, we selected BMI, which affects metabolic factors, as well as the variables included in the multiple logistic regression analysis. The Bayesian Network analysis revealed that AST, WBISI and hepatic fibrosis were directly associated with an elevated AFP level (Fig. 2). Under conditions of AST $\geq 50$ IU/L, WBISI $<5.0$ and fibrosis stage 3-4, $85 \%$ of the patients were presumed to have an elevated serum AFP level. On the other hand, when AST was $\geq 50 \mathrm{IU} / \mathrm{L}$ and fibrosis was stage $3-4,71 \%$ of the patients with WBISI $\geq 5.0$ were presumed to have a low serum AFP level (Table 3$)$.

\section{Pilot study}

The median duration of the intervention was 182 days (range: 91-380 days). The baseline characteristics of the patients included in the prospective study and the changes in parameters after the lifestyle intervention are presented in Table 4. The VFA $(\mathrm{p}=0.001)$ and BMI $(\mathrm{p}<0.001)$ decreased significantly after the lifestyle intervention. The leptin/adiponectin ratio decreased $(\mathrm{p}=0.028)$ along with the reduction of visceral fat. In terms of hematology and biochemical data, the platelet count $(\mathrm{p}=0.026)$ and levels of $\gamma$-GTP $(\mathrm{p}=$ $0.04)$, total cholesterol $(\mathrm{p}=0.042)$, triglycerides $(\mathrm{p}=0.008)$, creatinine $(\mathrm{p}=0.025)$, total protein $(\mathrm{p}=0.006)$ and albumin $(\mathrm{p}=0.004)$ decreased. Among the markers of glucose metabolism, FPG $(\mathrm{p}<0.001)$, FSI $(\mathrm{p}=0.001)$ and HOMA-IR $(\mathrm{p}<$ $0.001)$ decreased after the intervention, while WBISI increased $[p<0.001$ (Fig. 3)]. The serum AFP level also decreased significantly after the intervention [p=0.002 (Fig. 3)]. 
Table 1. Characteristics of Patients according to the Serum $\alpha$-fetoprotein Levels

\begin{tabular}{|c|c|c|c|}
\hline & $\begin{array}{l}\mathrm{AFP}<10 \mathrm{ng} / \mathrm{mL} \\
\mathrm{n}=206\end{array}$ & $\begin{array}{l}\mathrm{AFP} \geq 10 \mathrm{ng} / \mathrm{mL} \\
\mathrm{n}=59\end{array}$ & $\mathrm{p}$ value \\
\hline Males/females & $105 / 101$ & $32 / 27$ & 0.768 \\
\hline Age (years) & $58(24-75)$ & $59(39-74)$ & 0.170 \\
\hline BMI $\left(\mathrm{kg} / \mathrm{m}^{2}\right)$ & $22.9(15.7-33.8)$ & $23.7(17.9-31.1)$ & 0.033 \\
\hline $\begin{array}{l}\text { Alcohol intake, } \\
\text { none/occasionally/regularly/ } \\
\text { unknown }\end{array}$ & $73 / 71 / 54 / 8$ & $27 / 15 / 14 / 3$ & 0.437 \\
\hline $\begin{array}{l}\text { History of IFN therapy, } \\
\text { yes/no/unknown }\end{array}$ & $54 / 148 / 4$ & $21 / 37 / 1$ & 0.370 \\
\hline Platelet count $\left(\times 10^{4} / \mu \mathrm{L}\right)$ & $16.7(5.5-42.2)$ & $12.8(5.7-25.2)$ & $<0.001$ \\
\hline AST (IU/L) & $40(17-163)$ & $68(15-233)$ & $<0.001$ \\
\hline ALT (IU/L) & $43(9-395)$ & $75(19-243)$ & $<0.001$ \\
\hline$\gamma-\mathrm{GTP}(\mathrm{IU} / \mathrm{L})$ & $30(3-509)$ & $60(13-323)$ & $<0.001$ \\
\hline Total cholesterol (mg/dL) & $176(94-314)$ & $169(83-242)$ & 0.093 \\
\hline Triglyceride (mg/dL) & $87(36-607)$ & $104(49-245)$ & 0.002 \\
\hline HDL-C (mg/dL) & $49(23-108)^{\mathrm{a}}$ & $43(24-79)^{\mathrm{b}}$ & 0.016 \\
\hline Uric acid (mg/dL) & $5.4(2.4-10.5)^{\mathrm{c}}$ & $5.8(2.1-8.1)^{\mathrm{d}}$ & 0.194 \\
\hline Creatinine (mg/dL) & $0.7(0.5-1.9)$ & $0.7(0.3-1.4)$ & 0.348 \\
\hline Total protein $(\mathrm{g} / \mathrm{dL})$ & $7.2(5.9-9.9)$ & $7.2(5.7-8.6)$ & 0.530 \\
\hline Albumin (g/dL) & $4.2(3.2-5.2)$ & $4.0(2.7-4.7)$ & $<0.001$ \\
\hline $\mathrm{FPG}(\mathrm{mg} / \mathrm{dL})$ & $87(67-133)$ & $88(75-118)$ & 0.867 \\
\hline 2-h glucose (mg/dL) & $117(57-338)$ & $136(85-305)$ & $<0.001$ \\
\hline FSI $(\mu \mathrm{U} / \mathrm{mL})$ & $7(2-24)$ & $11(3-34)$ & $<0.001$ \\
\hline $2-\mathrm{h}$ insulin $(\mu \mathrm{U} / \mathrm{mL})$ & $47(6-500)$ & $93(20-294)$ & $<0.001$ \\
\hline HOMA-IR & $1.4(0.3-7.7)$ & $2.4(0.6-8.0)$ & $<0.001$ \\
\hline WBISI & $5.6(1.2-23.3)$ & $2.9(1.0-12.3)$ & $<0.001$ \\
\hline HOMA- $\beta$ & $99(24-630)$ & $148(41-666)$ & $<0.001$ \\
\hline $\begin{array}{l}\text { Glucose tolerance: } \\
\text { NGT/non-NGT }\end{array}$ & $149 / 57$ & $30 / 29$ & 0.003 \\
\hline $\operatorname{VFA}\left(\mathrm{cm}^{2}\right)$ & $60(10-221)^{e}$ & $94(12-163)^{\mathrm{f}}$ & $<0.001$ \\
\hline \multicolumn{4}{|l|}{ Liver histology } \\
\hline Inflammation: A0/A1/A2/A3 & $8 / 132 / 63 / 3$ & $0 / 19 / 31 / 9$ & $<0.001$ \\
\hline Fibrosis: F0/F1/F2/F3/F4 & $10 / 125 / 56 / 14 / 1$ & $0 / 12 / 21 / 23 / 3$ & $<0.001$ \\
\hline Steatosis $(\%):<5 / 5-30 / \geq 30$ & $159 / 42 / 5$ & $36 / 15 / 8$ & 0.012 \\
\hline
\end{tabular}

Values are median (range) or number of patients. BMI: body mass index, IFN: interferon, AFP: $\alpha$-fetoprotein, AST: aspartate aminotransferase, ALT: alanine aminotransferase, $\gamma$-GTP: $\gamma$-glutamyl transpeptidase, HDL-C: high-density lipoprotein cholesterol, FPG: fasting plasma glucose, FSI: fasting serum insulin, HOMA-IR: homeostasis model assessment for insulin resistance, WBISI: whole-body insulin sensitivity index, HOMA- $\beta$ : homeostasis model assessment for $\beta$ cell function, NGT: normal glucose tolerance, VFA: visceral fat area. ${ }^{\mathrm{a}} \mathrm{n}=195,{ }^{\mathrm{b}} \mathrm{n}=$ $56,{ }^{\mathrm{c}} \mathrm{n}=204,{ }^{\mathrm{d}} \mathrm{n}=58,{ }^{\mathrm{e}} \mathrm{n}=119,{ }^{\mathrm{f}} \mathrm{n}=40$.

Table 2. Factors Associated with Elevated Serum $\alpha$ fetoprotein Level (Multiple Logistic Regression Analysis)

\begin{tabular}{lllc}
\hline Variables & OR & $95 \%$ CI & p value \\
\hline Platelet $<15 \times 10^{4} / \mu \mathrm{L}$ & 2.74 & $1.27-5.91$ & 0.010 \\
AST $\geq 50 \mathrm{IU} / \mathrm{L}$ & 3.46 & $1.24-9.65$ & 0.018 \\
$\mathrm{ALT} \geq 50 \mathrm{IU} / \mathrm{L}$ & 0.68 & $0.24-1.98$ & 0.482 \\
$\gamma$-GTP $\geq 35 \mathrm{IU} / \mathrm{L}$ & 2.43 & $1.03-5.71$ & 0.042 \\
Triglyceride $\geq 90 \mathrm{mg} / \mathrm{dL}$ & 1.18 & $0.55-2.55$ & 0.670 \\
Albumin $<4 \mathrm{~g} / \mathrm{dL}$ & 0.86 & $0.37-1.98$ & 0.724 \\
WBISI $<5.0$ & 3.55 & $1.56-8.09$ & 0.003 \\
Hepatic inflammation A2-A3 & 1.84 & $0.85-4.00$ & 0.124 \\
Hepatic fibrosis F3-F4 & 3.71 & $1.43-9.58$ & 0.007 \\
\hline AST: aspartate aminotransferase, ALT: alanine aminotransferase, \\
$\gamma$-GTP: $\gamma$-glutamyl transpeptidase, WBISI: whole-body insulin \\
sensitivity index
\end{tabular}
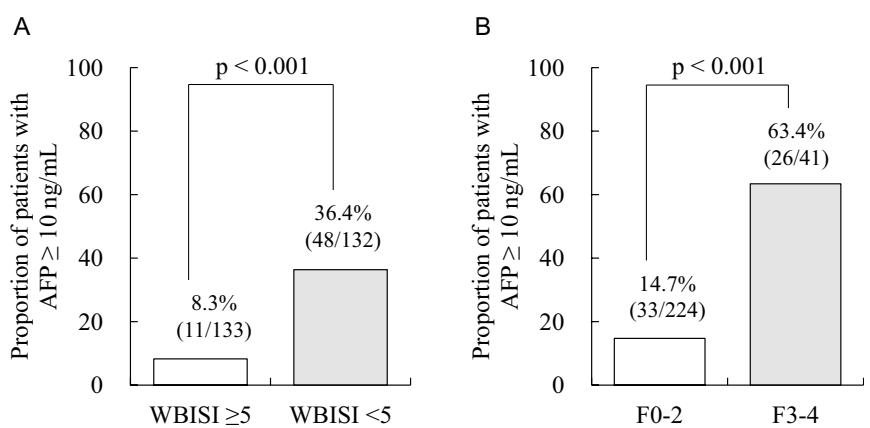

Figure 1. Prevalence of an elevated $\alpha$-fetoprotein level $(\geq 10$ ng/mL) according to the (A) whole-body insulin sensitivity index and (B) hepatic fibrosis. AFP: $\alpha$-fetoprotein, WBISI: whole-body insulin sensitivity index 


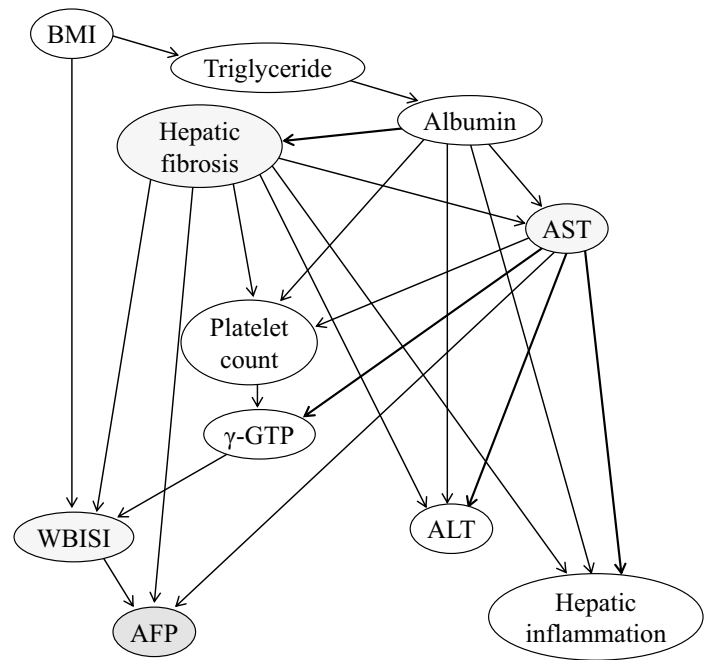

Figure 2. Bayesian Network analysis of the associations between an elevated serum $\alpha$-fetoprotein level and the clinical factors. AFP: $\alpha$-fetoprotein, WBISI: whole-body insulin sensitivity index, BMI: body mass index, AST: aspartate aminotransferase, ALT: alanine aminotransferase, $\gamma$-GTP: $\gamma$-glutamyl transpeptidase

\section{Discussion}

In the present series of studies, we first demonstrated that systemic IR directly influences the elevation of the AFP level in patients with chronic HCV infection based on the results of multivariate and causal-relationship analyses.

The multiple logistic regression analysis showed that a decreased platelet count, increased serum AST and $\gamma$-GTP levels, whole-body IR and advanced hepatic fibrosis were independently associated with an elevated AFP level. Several studies have shown that an elevated AFP level is associated with a decreased platelet count, an increased AST level and advanced fibrosis in CHC patients without HCC (5-7), consistent with our findings. Furthermore, the Bayesian Network analysis, which has the ability to assess causal relationships based on conditional probabilities, revealed that an elevated AST level, whole-body IR and advanced fibrosis were directly associated with an elevated AFP level.

In terms of markers of glucose metabolism, WBISI, an index of whole-body IR, was selected as a feasible marker for AFP elevation, whereas HOMA-IR, an index of hepatic IR, was not selected. These results suggest that IR associated with an increased AFP level may be induced by an HCVinfected liver as well as obesity or other metabolic conditions, as systemic IR develops simultaneously in multiple organs, including the liver, skeletal muscle and adipose tissue (30). In fact, the Bayesian Network analysis did not reveal a relationship between an elevated AFP level and the HOMA-IR (data not shown).

Several researchers have reported that IR in HCV-infected patients is closely associated with hepatic fibrosis $(12,16-18)$. Our Bayesian Network analysis also identi-
Table 3. Bayesian Network Analysis of the Incidence of Elevated Serum $\alpha$-fetoprotein

\begin{tabular}{llll}
\hline Parameters & & & Probability \\
\hline WBISI $\geq 5$ & AST $<50$ & F0-2 & 0.042 \\
WBISI $\geq 5$ & AST $<50$ & F3-4 & 0.333 \\
WBISI $\geq 5$ & AST $\geq 50$ & F0-2 & 0.219 \\
WBISI $\geq 5$ & AST $\geq 50$ & F3-4 & 0.286 \\
WBISI $<5$ & AST $<50$ & F0-2 & 0.169 \\
WBISI $<5$ & AST $<50$ & F3-4 & 0.400 \\
WBISI $<5$ & AST $\geq 50$ & F0-2 & 0.356 \\
WBISI $<5$ & AST $\geq 50$ & F3-4 & 0.846 \\
\hline \multicolumn{7}{l}{ WBISI: whole-body insulin } & sensitivity & index, AST: \\
aspartate aminotransferase & &
\end{tabular}

fied a direct relationship between whole-body IR and hepatic fibrosis. However, both systemic IR and advanced fibrosis were independently and directly associated with an elevated AFP level. These results suggest that it may be possible to decrease the serum AFP level by improving IR, even in patients with advanced hepatic fibrosis.

Although no reports have described an association between the serum AFP and $\gamma$-GTP levels, it is well known that $\gamma$-GTP plays important roles in the generation of oxidative stress (31) and is correlated with IR (32). The Bayesian Network analysis also showed that the $\gamma$-GTP level influences the serum AFP level via the effects of whole-body IR.

In the second part of this study, we showed that prospective lifestyle modification can improve metabolic factors, including systemic IR and the serum AFP level. We found that the leptin/adiponectin ratio, a useful marker of metabolic syndrome in the general population that is correlated with IR in individuals with or without diabetes (33-35), decreased after the intervention. Therefore, we presumed that the reduction in visceral fat achieved with the lifestyle intervention caused a decrease in the leptin/adiponectin ratio, which then improved IR. However, we found no changes in the sTNFR2 levels, a marker for tumor necrosis factor, a key cytokine involved in $\mathrm{HCV}$-associated IR and obesityassociated IR (20,35-38), despite the reduction in body weight observed in this study. We previously reported that eradication of $\mathrm{HCV}$ by IFN decreases the serum sTNFR2 level and improves whole-body IR (20). Therefore, these results suggest that IR and elevated AFP levels in HCVinfected patients may be inhibited by the eradication of $\mathrm{HCV}$ with antiviral therapy.

Unexpectedly, the platelet count, which was negatively correlated with an elevated AFP level in the retrospective study, decreased after the lifestyle intervention. We assume that the reduction of the platelet count reflects an improvement in systemic inflammation, a key feature of obesity and DM (39). The adiponectin levels, which are inversely related to adiposity, decreased slightly after the lifestyle intervention, although the changes were not statistically significant. Because the serum adiponectin levels are affected by hepatic fibrosis, regardless of the cause of liver disease (40), the effects of lifestyle intervention on the serum adiponectin levels in $\mathrm{HCV}$-infected patients may differ from those observed 
Table 4. Patient Characteristics and Effects of the Lifestyle Intervention on Clinical Characteristics

\begin{tabular}{|c|c|c|c|}
\hline & Baseline & After & $\mathrm{p}$ value \\
\hline Males/females & $11 / 9$ & - & - \\
\hline Age (years) & $60(37-71)$ & - & - \\
\hline BMI $\left(\mathrm{kg} / \mathrm{m}^{2}\right)$ & $25.9(18.9-30.5)$ & $25.0(17.8-29.2)$ & $<0.001$ \\
\hline $\begin{array}{l}\text { Alcohol intake, } \\
\text { none/occasionally/regularly }\end{array}$ & $13 / 6 / 1$ & - & - \\
\hline History of IFN, yes/no & $9 / 11$ & - & - \\
\hline Platelet count $\left(\times 10^{4} / \mu \mathrm{L}\right)$ & $15.1(10.5-23.7)$ & $14.3(8.1-20.6)$ & 0.026 \\
\hline $\operatorname{AST}(\mathrm{IU} / \mathrm{L})$ & $45(20-155)$ & $42(18-202)$ & 0.251 \\
\hline ALT (IU/L) & $54(18-227)$ & $44(15-266)$ & 0.173 \\
\hline$\gamma-\mathrm{GTP}(\mathrm{IU} / \mathrm{L})$ & $43(11-137)$ & $35(11-110)$ & 0.040 \\
\hline Total cholesterol (mg/dL) & $172(121-221)$ & $163(117-209)$ & 0.042 \\
\hline Triglyceride (mg/dL) & $108(48-230)$ & $87(33-238)$ & 0.008 \\
\hline HDL-C (mg/dL) & $42(24-73)$ & $40(29-75)$ & 0.419 \\
\hline Uric acid (mg/dL) & $5.8(2.9-8.9)$ & $5.8(3.0-8.5)$ & 0.337 \\
\hline Creatinine $(\mathrm{mg} / \mathrm{dL})$ & $0.77(0.46-0.98)$ & $0.75(0.40-0.93)$ & 0.025 \\
\hline Total protein $(\mathrm{g} / \mathrm{dL})$ & $7.5(6.8-8.6)$ & $7.3(6.3-8.8)$ & 0.006 \\
\hline Albumin $(g / d L)$ & $4.2(3.5-4.9)$ & $4.1(3.2-4.5)$ & 0.004 \\
\hline $\mathrm{FPG}(\mathrm{mg} / \mathrm{dL})$ & $101(85-110)$ & $89(75-107)$ & $<0.001$ \\
\hline 2 -h glucose $(\mathrm{mg} / \mathrm{dL})$ & $140(89-305)$ & $120(78-202)$ & 0.130 \\
\hline FSI $(\mu \mathrm{U} / \mathrm{mL})$ & $13(9-18)$ & $9(6-21)$ & 0.001 \\
\hline 2-h insulin $(\mu \mathrm{U} / \mathrm{mL})$ & $88(31-227)$ & $66(18-189)$ & 0.057 \\
\hline HOMA-IR & $2.8(2.3-4.7)$ & $1.9(1.2-4.8)$ & $<0.001$ \\
\hline WBISI & $3.0(1.5-4.2)$ & $4.2(1.4-7.8)$ & $<0.001$ \\
\hline HOMA- $\beta$ & $135(75-256)$ & $127(58-299)$ & 0.737 \\
\hline $\begin{array}{l}\text { Glucose tolerance, } \\
\text { NGT/IGT/DM }\end{array}$ & $10 / 8 / 2$ & $15 / 4 / 1$ & 0.153 \\
\hline $\operatorname{AFP}(\mathrm{ng} / \mathrm{mL})$ & $7.5(3.0-47.0)$ & $7.0(2.0-30.5)$ & 0.002 \\
\hline Adiponectin $(\mu \mathrm{g} / \mathrm{mL})$ & $9.6(1.9-20.7)^{\mathrm{a}}$ & $8.6(2.3-25.1)^{\mathrm{b}}$ & 0.463 \\
\hline Leptin $(\mathrm{ng} / \mathrm{mL})$ & $9.0(2.1-16.2)^{\mathrm{a}}$ & $5.2(1.3-14.6)^{\mathrm{b}}$ & 0.039 \\
\hline Leptin/adiponectin ratio & $1.1(0.2-4.9)^{\mathrm{a}}$ & $1.5(0.4-12.0)^{\mathrm{b}}$ & 0.028 \\
\hline sTNFR2 $(\mathrm{pg} / \mathrm{mL})$ & $3170(2010-5000)^{\mathrm{a}}$ & $3050(1600-5000)^{\mathrm{b}}$ & 0.938 \\
\hline $\operatorname{VFA}\left(\mathrm{cm}^{2}\right)$ & $96(31-220)$ & $68(12-159)$ & 0.001 \\
\hline \multicolumn{4}{|l|}{ Liver histology } \\
\hline Inflammation: A0/A1/A2/A3 & $0 / 12 / 7 / 1$ & - & - \\
\hline Fibrosis: F0/F1/F2/F3/F4 & $0 / 8 / 9 / 3 / 0$ & - & - \\
\hline Steatosis $(\%):<5 / 5-30 / \geq 30$ & $10 / 8 / 2$ & - & - \\
\hline \multicolumn{4}{|c|}{$\begin{array}{l}\text { Values are medians (range) or number of patients. BMI: body mass index, IFN: } \\
\text { interferon, AST: aspartate aminotransferase, ALT: alanine aminotransferase, } \gamma \text {-GTP: } \\
\gamma \text {-glutamyl transpeptidase, HDL-C: high-density lipoprotein cholesterol, FPG: fasting } \\
\text { plasma glucose, FSI: fasting serum insulin, HOMA-IR: homeostasis model assessment } \\
\text { for insulin resistance, WBISI: whole-body insulin sensitivity index, HOMA- } \beta \text { : } \\
\text { homeostasis model assessment for } \beta \text { cell function, NGT: normal glucose tolerance, IGT: } \\
\text { impaired glucose tolerance, DM: diabetes mellitus, AFP: } \alpha \text {-fetoprotein, sTNFR2: } \\
\text { soluble tumor necrosis factor receptor } 2 \text {, VFA: visceral fat area. }{ }^{a} n=19,{ }^{b}=18 \text {. }\end{array}$} \\
\hline
\end{tabular}
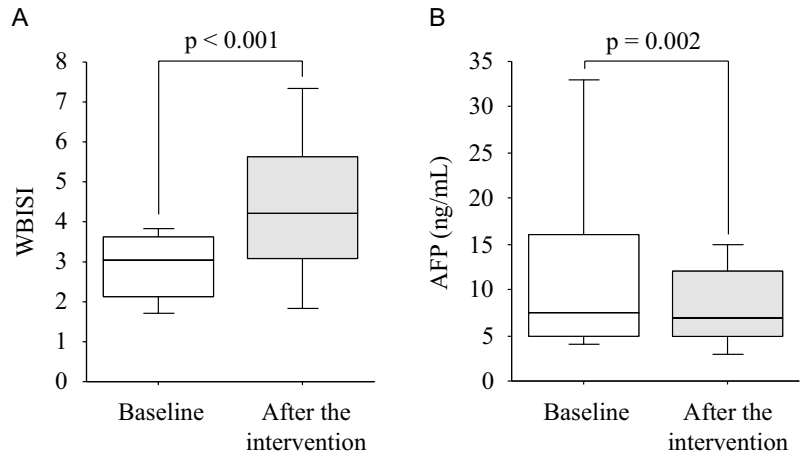

Figure 3. Effects of the lifestyle intervention on the (A) whole-body insulin sensitivity index and (B) serum $\alpha$-fetoprotein level. AFP: $\alpha$-fetoprotein, WBISI: whole-body insulin sensitivity index in healthy subjects.

Several reports have shown that reductions in the serum AFP levels following IFN treatment in patients with $\mathrm{CHC}$ can help to prevent the development of $\mathrm{HCC}$, irrespective of viral eradication $(10,11,41)$. However, a large, randomized controlled trial recently showed that long-term maintenance peg-IFN therapy in patients with advanced CHC does not prevent liver-related deaths and actually increases the overall mortality, primarily due to non-liver-related causes (42). Therefore, the long-term administration of IFN to prevent HCC is not recommended in patients with advanced hepatic fibrosis. In $\mathrm{HCV}$-infected patients, we previously reported that an increased BMI is associated with an increased risk of HCC at a younger age (43) and that the occurrence of hyperglycemia after a glucose load is a significant risk factor for the development of HCC (44). Taken together, it is likely that improvements in systemic IR and/or glucose me- 
tabolism via appropriate lifestyle modification can help to safely prevent hepatocarcinogenesis, even in patients with advanced $\mathrm{CHC}$.

One limitation of our study is that we did not measure the fucosylated fraction of AFP (AFP-L3), an accepted specific marker for HCC (45). Therefore, future studies should determine which fraction of AFP is decreased by lifestyle interventions. Another limitation is that we did not evaluate the changes in alcohol intake after the lifestyle intervention. Changes in alcohol intake may affect IR and the serum AFP level.

In conclusion, this study showed that whole-body IR, an elevated AST level and advanced fibrosis are independently and directly correlated with an elevated AFP level in patients with $\mathrm{CHC}$. We also found that lifestyle modification can reduce the AFP level and whole-body IR. To our knowledge, this is the first report to examine the relationship between the serum AFP level and systemic IR and to show that lifestyle modification can reduce the serum AFP level. Further prospective studies are needed to confirm whether the reduction in the serum AFP level achieved via lifestyle modification can prevent hepatocarcinogenesis in $\mathrm{HCV}$ infected patients.

\section{The authors state that they have no Conflict of Interest (COI).}

\section{References}

1. Lauer G, Walker BD. Hepatitis C virus infection. N Engl J Med 345: 41-52, 2001.

2. Poynard T, Yuen MF, Ratziu V, Lai CL. Viral hepatitis C. Lancet 362: 2095-2100, 2003.

3. El-Serag HB, Rudolph KL. Hepatocellular carcinoma: epidemiology and molecular carcinogenesis. Gastroenterology 132: 25572576, 2007.

4. Akuta N, Suzuki F, Kawamura Y, et al. Predictors of viral kinetics to peginterferon plus ribavirin combination therapy in Japanese patients infected with hepatitis C virus genotype $1 \mathrm{~b}$. J Med Virol 79: 1686-1695, 2007.

5. Di Bisceglie AM, Sterling RK, Chung RT, et al. Serum alphafetoprotein levels in patients with advanced hepatitis C: results from the HALT-C Trial. J Hepatol 43: 434-441, 2005.

6. Tateyama M, Yatsuhashi H, Taura N, et al. Alpha-fetoprotein above normal levels as a risk factor for the development of hepatocellular carcinoma in patients infected with hepatitis $\mathrm{C}$ virus. $\mathrm{J}$ Gastroenterol 46: 92-100, 2011.

7. Chu CW, Hwang SJ, Luo JC, et al. Clinical, virologic, and pathologic significance of elevated serum alpha-fetoprotein levels in patients with chronic hepatitis C. J Clin Gastroenterol 32: 240244, 2001.

8. Asahina $\mathrm{Y}$, Tsuchiya $\mathrm{K}$, Tamaki N, et al. Effect of aging on risk for hepatocellular carcinoma in chronic hepatitis $\mathrm{C}$ virus infection. Hepatology 52: 518-527, 2010.

9. Tamura Y, Yamagiwa S, Aoki Y, et al. Serum alpha-fetoprotein levels during and after interferon therapy and the development of hepatocellular carcinoma in patients with chronic hepatitis C. Dig Dis Sci 54: 2530-2537, 2009.

10. Arase Y, Ikeda K, Suzuki F, et al. Prolonged-interferon therapy reduces hepatocarcinogenesis in aged-patients with chronic hepatitis C. J Med Virol 79: 1095-1102, 2007.

11. Yoshida H, Shiratori Y, Moriyama M, et al. Interferon therapy re- duces the risk for hepatocellular carcinoma: national surveillance program of cirrhotic and noncirrhotic patients with chronic hepatitis C in Japan. Ann Intern Med 131: 174-181, 1999.

12. D'Souza R, Sabin CA, Foster GR. Insulin resistance plays a significant role in liver fibrosis in chronic hepatitis $\mathrm{C}$ and in the response to antiviral therapy. Am J Gastroenterol 100: 1509-1515, 2005.

13. Romero-Gómez M, Del Mar Viloria M, Andrade RJ, et al. Insulin resistance impairs sustained response rate to peginterferon plus ribavirin in chronic hepatitis $C$ patients. Gastroenterology 128: 636-641, 2005.

14. Mizuta T, Kawaguchi Y, Eguchi Y, et al. Whole-body insulin sensitivity index is a highly specific predictive marker for virological response to peginterferon plus ribavirin therapy in chronic hepatitis $\mathrm{C}$ patients with genotype $1 \mathrm{~b}$ and high viral load. Dig Dis Sci 55: 183-189, 2010.

15. Eslam M, Aparcero R, Kawaguchi T, et al. Meta-analysis: insulin resistance and sustained virological response in hepatitis C. Aliment Pharmacol Ther 34: 297-305, 2011.

16. Hui JM, Sud A, Farrell GC, et al. Insulin resistance is associated with chronic hepatitis $\mathrm{C}$ virus infection and fibrosis progression [corrected]. Gastroenterology 125: 1695-1704, 2003.

17. Fartoux L, Poujol-Robert A, Guéchot J, Wendum D, Poupon R, Serfaty L. Insulin resistance is a cause of steatosis and fibrosis progression in chronic hepatitis C. Gut 54: 1003-1008, 2005.

18. Muzzi A, Leandro G, Rubbia-Brandt L, et al. Insulin resistance is associated with liver fibrosis in non-diabetic chronic hepatitis $\mathrm{C}$ patients. J Hepatol 42: 41-46, 2005.

19. El-Serag HB, Tran T, Everhart JE. Diabetes increases the risk of chronic liver disease and hepatocellular carcinoma. Gastroenterology 126: 460-468, 2004.

20. Kawaguchi Y, Mizuta T, Oza N, et al. Eradication of hepatitis $C$ virus by interferon improves whole-body insulin resistance and hyperinsulinaemia in patients with chronic hepatitis C. Liver Int 29: 871-877, 2009.

21. Eguchi Y, Mizuta T, Ishibashi E, et al. Hepatitis $C$ virus infection enhances insulin resistance induced by visceral fat accumulation. Liver Int 29: 213-220, 2009.

22. Alberti KG, Zimmet PZ. Definition, diagnosis and classification of diabetes mellitus and its complications. Part 1: Diagnosis and classification of diabetes mellitus provisional report of a WHO consultation. Diabet Med 15: 539-553, 1998.

23. Matthews DR, Hosker JP, Rudenski AS, Naylor BA, Treacher DF, Turner RC. Homeostasis model assessment: insulin resistance and beta-cell function from fasting plasma glucose and insulin concentrations in man. Diabetologia 28: 412-419, 1985.

24. Matsuda M, DeFronzo RA. Insulin sensitivity indices obtained from oral glucose tolerance testing. Comparison with the euglycemic insulin clamp. Diabetes Care 22: 1462-1470, 1999.

25. Yoshizumi T, Nakamura T, Yamane M, et al. Abdominal fat: standardized technique for measurement at CT. Radiology 211: 283286, 1999.

26. Bedossa P, Poynard T; the METAVIR Cooperative Study Group. An algorithm for the grading of activity in chronic hepatitis $\mathrm{C}$. Hepatology 24: 289-293, 1996.

27. Exercise and Physical Activity Guide for Health Promotion 2006. http://www0.nih.go.jp/eiken/programs/pdf/exercise_guide.pdf

28. Hoot N, Aronsky D. Using Bayesian networks to predict survival of liver transplant patients. AMIA Annu Symp Proc 345-349, 2005.

29. Li Z, Chan C. Inferring pathways and networks with a Bayesian framework. FASEB J 18: 746-748, 2004.

30. Groop LC, Bonadonna RC, Shank M, Petrides AS, DeFronzo RA. Role of free fatty acids and insulin in determining free fatty acid and lipid oxidation in man. J Clin Invest 87: 83-89, 1991.

31. Zhang H, Forman HJ. Redox regulation of $\gamma$-glutamyl transpepti- 
dase. Am J Respir Cell Mol Biol 41: 509-515, 2009.

32. Bonnet F, Ducluzeau PH, Gastaldelli A, et al. Liver enzymes are associated with hepatic insulin resistance, insulin secretion, and glucagon concentration in healthy men and women. Diabetes 60: 1660-1667, 2011.

33. Kotani K, Sakane N. Leptin: adiponectin ratio and metabolic syndrome in the general Japanese population. Korean J Lab Med 31: 162-166, 2011.

34. Finucane FM, Luan J, Wareham $\mathrm{NJ}$, et al. Correlation of the leptin:adiponectin ratio with measures of insulin resistance in nondiabetic individuals. Diabetologia 52: 2345-2349, 2009.

35. Oda N, Imamura $S$, Fujita $T$, et al. The ratio of leptin to adiponectin can be used as an index of insulin resistance. Metabolism 57: 268-273, 2008.

36. Lecube A, Hernández C, Genescà J, Simó R. Proinflammatory cytokines, insulin resistance, and insulin secretion in chronic hepatitis C patients: a case-control study. Diabetes Care 29: 1096-1101, 2006.

37. Knobler H, Zhornicky T, Sandler A, Haran N, Ashur Y, Schattner A. Tumor necrosis factor- $\alpha$-induced insulin resistance may mediate the hepatitis $\mathrm{C}$ virus-diabetes association. Am J Gastroenterol 98: 2751-2756, 2003.

38. Hotamisligil GS, Shargill NS, Spiegelman BM. Adipose expression of tumor necrosis factor-alpha: direct role in obesity-linked insulin resistance. Science 259: 87-91, 1993.
39. Wellen KE, Hotamisligil GS. Inflammation, stress, and diabetes. J Clin Invest 115: 1111-1119, 2005.

40. Kaser S, Moschen A, Kaser A, et al. Circulating adiponectin reflects severity of liver disease but not insulin sensitivity in liver cirrhosis. J Intern Med 258: 274-280, 2005.

41. Murashima S, Tanaka M, Haramaki $M$, et al. A decrease in AFP level related to administration of interferon in patients with chronic hepatitis C and a high level of AFP. Dig Dis Sci 51: 808812, 2006.

42. Di Bisceglie AM, Stoddard AM, Dienstag JL, et al; HALT-C Trial Group. Excess mortality in patients with advanced chronic hepatitis $\mathrm{C}$ treated with long-term peginterferon. Hepatology 53: 11001108, 2011.

43. Akiyama T, Mizuta T, Kawazoe S, et al. Body mass index is associated with age-at-onset of $\mathrm{HCV}$-infected hepatocellular carcinoma patients. World J Gastroenterol 17: 914-921, 2011.

44. Takahashi H, Mizuta T, Eguchi Y, et al. Post-challenge hyperglycemia is a significant risk factor for the development of hepatocellular carcinoma in patients with chronic hepatitis C. J Gastroenterol 46: 790-798, 2011.

45. Aoyagi Y, Isokawa O, Suda T, Watanabe M, Suzuki Y, Asakura H. The fucosylation index of alpha-fetoprotein as a possible prognostic indicator for patients with hepatocellular carcinoma. Cancer 83: 2076-2082, 1998.

(C) 2013 The Japanese Society of Internal Medicine http://www.naika.or.jp/imonline/index.html 